\title{
High mobility group box 1 protein in the central nervous system
}

\author{
Norbert Wąsik, Roman Jankowski, Bartosz Sokół, Hinna Shahid \\ Department of Neurosurgery, Poznan University of Medical Science, Poland
}

\begin{abstract}
High-mobility group box 1 protein (HMGB1) is a multifunctional protein originally identified as a nuclear transcription modifier. Two pathways are leading to HMGB1 release to the extracellular space i.e. active secretion triggered by noxious stimulation and passive leakage due to necrotic membrane damage. Binding with receptors for advanced glycation end products (RAGE) as well as Toll-like receptor 2 (TLR2) and TLR4 leads to nuclear factor $\kappa \mathrm{B}(\mathrm{NF}-\kappa \mathrm{B})$ activation and proinflammatory reaction in target cells. Secretion of cytokines, upregulation of adhesion molecules and chemoattraction are triggered by the extracellular HMGB1. Such ubiquitous and numerous protein plays a role in pathogenesis of many common diseases like sepsis, rheumatoid arthritis and pneumonia. Central nervous system (CNS) disorders are also mediated by HMGB1. Multiple studies highlight pivotal role of HMGB1 in acute pathologies of CNS like cerebral ischemia, aneurysmal subarachnoid hemorrhage as well as chronic degenerative disorders such as Alzheimer's disease and multiple sclerosis. Wide range of HMGB1 antagonists are currently investigated as novel therapeutic agents in sepsis, colitis and stroke. This review article provides basic information about HMGB1 protein and its role in the pathogenesis of CNS diseases.
\end{abstract}

Keywords: high mobility group box 1, amphoterine, HMGB1, central nervous system, stroke.

\section{Introduction}

High-mobility group box 1 (HMGB1) is a multifunctional protein and a promising target for new therapies. Novel discoveries in this field are gradually translated into clinically useful tools. At Poznan University of Medical Sciences Department of Neurosurgery, HMGB1 protein levels and its prognostic potential in subarachnoid hemorrhage patients is currently investigated. Dynamic development of proteomics and minimally invasive brain monitoring will allow us in the future to routinely identify entire proteome (set of proteins) of cerebrospinal fluid in order to accurately predict treatment outcome [1]. Every cell nucleus in our body consists of $5 \times 10^{6}$ copies of HMGB1 [2]. Loosely bound to the chromatin, HMGB1 is modifying transcription of various genes i.e. for steroid hormones, p53 and nuclear factor $\kappa \mathrm{B}(\mathrm{NF}-\kappa \mathrm{B})$ [3]. Knock-out rats die shortly after the birth because of massive organ failure and hypoglycemia [4]. HMGB1 as a damage-associat- ed molecular pattern (DAMP) leak out to extracellular space during necrosis to initiate immune response as well as repair processes. It was found that HMGB1 work as a chemoattractant and mitogen [5]. Second release pathway was found in the stimulated immunological cells (macrophages, monocytes), which are capable of active secretion of HMGB1 [6]. Discovery of HMGB1 involvement in pathogenesis of such common diseases like rheumatoid arthritis, sepsis, pneumonia and ischemic stroke demonstrates plurality of functions carried out by this protein [7].

\section{Material and methods}

A systematic review of PubMed and Scopus databases was carried out according to keywords: HMGB1, high mobility group box 1, central nervous system inflammation diseases. Articles were selected based on their accuracy and informative character. 


\section{The history of HMGB1}

HMGB1 was first identified in 1973 as a nuclear protein by Johns and colleagues $[8,9]$. This most numerous protein in the nucleus was firstly named HMG1, because of its affiliation to high mobility group (HMG) protein family. All its members have in common rapid migration in electrophoretic polyacrylamide gel [10]. HMGB1 coding gene is located on chromosome 13 [11]. Nomenclature revision was carried out in 2001 and new name (HMGB1) was established [12]. In 1991 Heikki Rauvala and colleagues have discovered membrane-bound protein form involved in neurite out growth promotion during fetal central nervous system (CNS) development [13]. Wang and colleagues carried out another significant research in 1991 identifying HMGB1 as a late cytokine mediator of sepsis. Moreover, administration of neutralizing anti-HMGB1 antibodies significantly improved survival in mice [6]. These discoveries triggered great interest to further investigate HMGB1 protein.

\section{The structure of HMGB1}

HMGB1 is a 25 kDa protein of 215 amino acids (Figure 1). It consists of 2 homologous, helical and positively charged, DNA-binding domains, namely A box and B box. Both of them are partially covered by a negatively charged acidic tail composed exclusively of glutamic and aspartic acids [7]. In the extracellular space B-box is essential to initiate inflammatory mediator production [14]. On the other hand, A-box is an antagonist of B-box [15]. Both domains appeared early in phylogenies, probably even before animalia and plantae kingdoms split, which means HMGB1 is an evolutionary old invention [16]. Numerous acetylation and phosphorylation sites were identified in HMGB1. Some of them are located in nuclear localization signals (NLS), amino acids sequences responsible for nuclear localization of protein [17]. During programmed cell death - apoptosis HMGB1 is also released, but oxidation of cysteine in position 106 prevents it from receptors binding and unnecessary immune system activation [16].

\section{HMGB1 is released during sudden or programmed cell death}

Thanks to Wang and colleagues we know that extracellular HMGB1 can initiate immunological response in surrounding cells [6]. There are two major pathways leading to HMGB1 release (Figure 2). First, common for all nucleated cells, is a passive leakage of protein caused by cell membrane damage during necrosis. This pathway is characteristic for endogenous damage-associated molecular pattern molecules (DAMPs) and can initiate sterile inflammation around necrotic tissues i.e. in ischemic stroke [18]. Second pathway of HMGB1 release is an active secretion from immunological cells (macrophages, neutrophils, microglia) but also from other types of cells (endothelium, astrocytes). This pathway is activated in infectious inflammation i.e. sepsis, where HMGB1 release is triggered by LPS stimulation [19]. It turned out that HMGB1 released passively and actively vary in structure, the actively secreted protein undergoes acetylation and phosphorylation prior to release, while the passively leaked out protein is nonmodified [20]. LPS stimulation is activating cytosolic enzymes responsible for these modifications. Constant circulation of HMGB1 between nucleus and cystosol (with strong nuclear predominance) is interrupted and HMGB1 is redirected to the extracellular space. Modified by activated enzymes, HMGB1 is secreted in unique fashion by secretory lysosomes [17]. Extracellular HMGB1 binds with the three main types of receptors i.e. receptor for advanced glycation end products (RAGE), Toll-like receptor 2 (TLR2) and Toll-like receptor 4 (TLR4) [21]. RAGE receptor is expressed on surface of macrophages, monocytes, microglia, neural and endothelial cells [22]. These types of cells are numerously represented in CNS. Binding of HMGB1 and other ligands to RAGE receptor, like S100 protein family members, results in chemoattraction, growth stimulation, immune cell differentiation and increased expression of

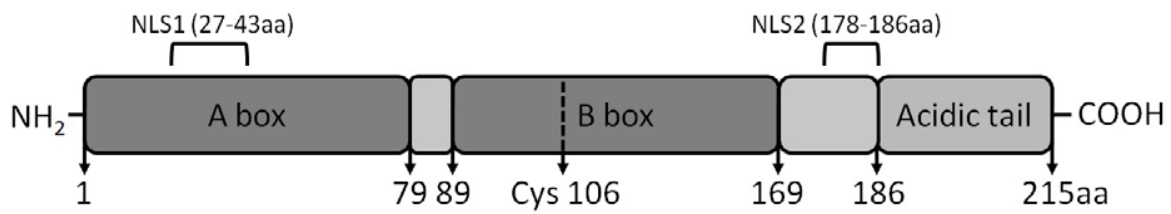

Figure 1. The structure of HMGB1. HMGB1 is a protein of 215 amino acids organized in two positively charged DNA binding domains (the $A$ and $B$ boxes) and a negatively charged acidic $C$-terminal tail composed of the aspartic and glutamic acids. The two nuclear localization signals susceptible to posttranslational modifications are also depicted. HMGB1 receptors binding affinity depends on oxidation of cysteine in position 106. Abbreviations: aa, amino acid; NLS, nuclear localization signal 


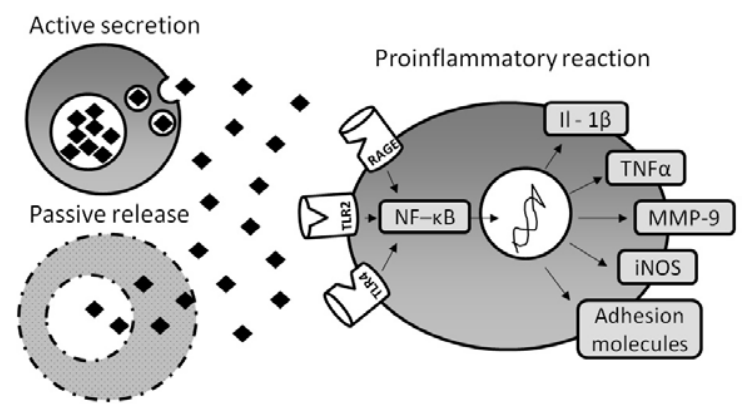

Figure 2. Major HMGB1 release pathways, target receptors and triggered reactions. Active secretion of HMGB1 from immunological (macrophages, neutrophils, microglia) and other types of cells (endothelium, astrocytes) is triggered by infectious as well as sterile stimulants (DAMP). Passive leakage of protein is caused by cell membrane damage during necrosis. Binding with three main receptors (RAGE, TLR2 and TLR4) leads to secretion of proinflammatory cytokines (II - 1B; TNF $\alpha$ ), upregulation of adhesion molecules, metalloproteinases (MMP-9) and nitric oxide synthase. All those reactions are mediated by activated nuclear factor $\kappa$ B. Abbreviations: DAMP, damageassociated molecular patterns; RAGE, receptor for advanced glycation end products; TLR, Toll-like receptor; II, interleukin; TNF, tumor necrosis factor; MMP, matrix metalloproteinase; NF- $\kappa B$, nuclear factor kappa B; iNOS, inducible nitric oxide synthase

RAGE and TLR2 receptors [23]. Toll-like receptors are pivotal for innate immunity. They recognize pathogens associated molecular pattern molecules (PAMPs). Their activation leads through $\mathrm{NF}-\kappa \mathrm{B}$ pathway to cytokine production and cell activation [24]. Inside nucleus HMGB1 carry out structural functions. Along with histone $\mathrm{H} 1, \mathrm{HMGB} 1$ regulates access to the genetic material and expression patterns of proteins $[25,26]$.

\section{HMGB1 in central nervous system}

HMGB1 is mainly investigated for its damaging impact on CNS, but this protein also mediates physiological processes in brain tissue. HMGB1 was found to be essential for proper forebrain development in rats. Interactions between HMGB1 and RAGE receptors are crucial for axonal sprouting and neurite out growth [13]. On the other hand, intraventricular injection of HMGB1 in rats causes general sickness syndrome manifested by fever, allodynia, change in animal behavior and weight loss due to anorexia [27]. Increase of interleukin - $1 \beta(\mathrm{II}-1 \beta)$ and tumor necrosis factor $\alpha$ (TNF- $\alpha$ ) concentration in brain tissue is another consequence of HMGB1 administration [28, 29]. HMGB1 takes part in pathogenesis of many neurological disorders. Most common of all CNS pathology, ischemic stroke is extensively investigated for HMGB1 involvement. In primary cultures of mouse neurons and glia cells, HMGB1 was found to promote chronic neuroinflammation mediated by NF $-\kappa B$ pathway. Same cell cultures under glucose and oxygen deprivation release HMGB1 to the extracellular space [30]. Increased level of HMGB1, leaked out form dying cells, was found in rats cerebrospinal fluid and plasma as well as in stroke patients plasma [31,
32]. Also, HMGB1 promotes glutamic acid (excitatory neurotransmitter) release from gliosomes as well as sensitizes neurons to the glutamate mediated injury in vitro [30,33]. Glutamate in high concentration causes uncontrolled calcium influx to neurons and protease, nuclease and phospholipase activation. This process called excitotoxicity is crucial for ischemic stroke pathogenesis [34]. Immune residual cells of CNS - microglia are considered to be the main source of proinflammatory cytokines released during ischemia. HMGB1 was found to trigger synthesis of matrix metalloproteinases (MMPs) and nitric oxide $[35,36]$. Also astrocytes, activated by HMGB1, secrete inflammatory mediators i. e. TNF- $\alpha[32,37,38]$. CNS is supplied by a dense system of blood vessels. Endothelial cells respond to HMGB1 stimulation by enhanced expression of intracellular adhesion molecule 1 (ICAM-1), vascular cell adhesion molecule 1 (VCAM-1) and E-selectin. This process promotes transendothelial migration of inflammatory cells and blood-brain barrier leakage [39]. Macrophages located around vessels and inside meninges respond to HMGB1 stimulation in the same fashion as microglia cells i.e. by producing proinflammatory cytokines, proteolytic enzymes and migration towards increasing HMGB1 concentration [40]. HMGB1 is involved in pathogenesis of chronic diseases like Alzheimer's disease (AD). High concentration of this protein was found in hippocampus in $A D$ animal model. Combination of HMGB1 with $\beta$-amyloid prolongs lysis of beta amyloid [27]. Elevated HMGB1 levels in serum and cerebrospinal fluid were found among patient suffering from meningitis [41], subarachnoid hemorrhage $[42,43]$ or CNS trauma [44]. 


\section{HMGB1 in therapy}

There are two main directions in therapy targeting HMGB1, prevention of protein release from cell or blockade of HMGB1 binding with receptors. According to those two pathways, therapeutic agents may be divided into two groups. Inhibition of active secretion is characteristic for ethyl pyruvate, epigallocatechin gallate (EGCG) and oxaliplatin $[45,46]$. Second and more numerous group of binding inhibitors include one of HMGB1 domains (A box), which is antagonistic to proinflammatory B box. Other members of this group are the soluble version of RAGE receptor (sRAGE), glycyrrhizic acid, simvastatin and atorvastatin [23]. Apart from CNS diseases, HMGB1 targeting therapies are already investigated in treatment of septic shock. Main advantage of anti-HMGB1 agents in treatment of this condition is their delayed administration [47]. Also recombinant A box, anti-RAGE antibodies as well as EGCG were proposed as effective agents in combating this lethal disease in animal model [48]. Ethyl pyruvate administration ameliorated colitis in mice and reduced intestinal cytokine production [49]. Single injection of cisplatine prevented HMGB1 secretion and caused transient symptom amelioration in collagen type II inducted arthritis (animal model of human rheumatoid arthritis) [45]. CNS diseases therapy is mainly focused on ischemic stroke. After inhibition of HMGB1 expression or by HMGB1 neutralization with antibodies, reduction of stroke tissue area was achieved in rats brain [50]. Also atrovastatin administration was found to be efficient in necrosis prevention [51]. Therapy with anti-HMGB1 antibodies was investigated in traumatic brain injuries [52]. The same agent was used efficiently in experimental treatment of multiple sclerosis in animal models. Amelioration of symptoms and slower progression of disease was achieved [53].

\section{Conclusion}

HMGB1 is an abundant and multifunctional protein strongly involved in both acute and chronic inflammation. Location and posttranslational modifications of this protein determine its function. HMGB1 may be a structural nuclear protein or extracellular mediator of sterile and infectious inflammation. Hopefully, the knowledge we are now gathering will help us in the future to design new therapies.

\section{Acknowledgements}

\section{Conflict of interest statement}

The authors declare that there is no conflict of interest in the authorship or publication of contribution.

\section{Funding sources}

There are no sources of funding to declare.

\section{References}

1. Guldbrandsen A, Vethe H, Farag Y, Oveland E, Garberg $\mathrm{H}$, Berle $\mathrm{M}$, et al. In-depth characterization of the cerebrospinal fluid proteome displayed through the CSF Proteome Resource (CSF-PR). Mol Cell Proteomics. 2014 Jul 18;13(11):3152-3163.

2. Comings DE, Harris DC. Nuclear proteins. II. Similarity of nonhistone proteins in nuclear sap and chromatin, and essential absence of contractile proteins from mouse liver nuclei. J Cell Biol. 1976 Aug;70(2 pt 1):440-452.

3. Hock R, Furusawa T, Ueda T, Bustin M. HMG chromosomal proteins in development and disease. Trends Cell Biol. 2007 Feb;17(2):72-79.

4. Calogero S, Grassi F, Aguzzi A, Voigtländer T, Ferrier P, Ferrari $S$, et al. The lack of chromosomal protein Hmg1 does not disrupt cell growth but causes lethal hypoglycaemia in newborn mice. Nat Genet. 1999 Jul;22(3):276-280.

5. Bianchi ME. HMGB1 loves company. J Leukoc Biol. 2009 Sep;86(3):573-576.

6. Wang $\mathrm{H}$, Bloom $\mathrm{O}$, Zhang M, Vishnubhakat JM, Ombrellino M, Che J, et al. HMG-1 as a late mediator of endotoxin lethality in mice. Science. 1999 Jul 9;285(5425):248-251.

7. Andersson U, Tracey KJ. HMGB1 is a therapeutic target for sterile inflammation and infection. Annu Rev Immunol. 2011 Jan;29:139-162.

8. Goodwin GH, Sanders C, Johns EW. A new group of chromatin-associated proteins with a high content of acidic and basic amino acids. Eur J Biochem. 1973 Sep 21;38(1):14-19.

9. Johns E, Goodwin C, Walker J, Sanders C. Chromosomal proteins related to histones. Ciba Found Symp. 1975;28:95-112.

10. Janko C, Filipović M, Munoz LE, Schorn C, Schett G, Ivanović-Burmazović I, et al. Redox modulation of HMGB1related signaling. Antioxid Redox Signal. 2014 Mar 1;20(7):1075-1085.

11. Ferrari S, Finelli P, Rocchi M, Bianchi ME. The active gene that encodes human high mobility group 1 protein (HMG1) contains introns and maps to chromosome 13. Genomics. 1996 Jul;35(2):367-371.

12. Bustin M. Revised nomenclature for high mobility group (HMG) chromosomal proteins. Trends Biochem Sci. 2001 Mar;26(3):152-153.

13. Merenmies J, Pihlaskari R, Laitinen J, Wartiovaara J, Rauvala H. 30-kDa heparin-binding protein of brain (amphoterin) involved in neurite outgrowth. Amino acid sequence and localization in the filopodia of the advancing plasma membrane. J Biol Chem. 1991 Sep 5;266(25):16722-16729.

14. Yang $H$, Lundbäck $P$, Ottosson $L$, Erlandsson-Harris $H$, Venereau $E$, Bianchi $M E$, et al. Redox modification of cysteine residues regulates the cytokine activity of high mobility group box-1 (HMGB1). Mol Med. 2012 Jan;18(8):250-259.

15. Yang H, Antoine DJ, Andersson U, Tracey KJ. The many faces of HMGB1: molecular structure-functional activity in inflammation, apoptosis, and chemotaxis. J Leukoc Biol. 2013 Jun;93(6):865-873. 
16. Lotze MT, Tracey KJ. High-mobility group box 1 protein (HMGB1): nuclear weapon in the immune arsenal. Nat Rev Immunol. 2005 Apr;5(4):331-342.

17. Bonaldi T, Talamo F, Scaffidi P, Ferrera D, Porto A, Bachi A, et al. Monocytic cells hyperacetylate chromatin protein HMGB1 to redirect it towards secretion. EMBO J. 2003 Oct 15;22(20):5551-5560.

18. Seong S-Y, Matzinger P. Hydrophobicity: an ancient damage-associated molecular pattern that initiates innate immune responses. Nat Rev Immunol. 2004 Jun;4(6):469-478.

19. Wang $H$, Yang $H$, Tracey KJ. Extracellular role of HMGB1 in inflammation and sepsis. J Intern Med. 2004 Mar;255(3):320-331.

20. Malarkey CS, Churchill MEA. The high mobility group box: the ultimate utility player of a cell. Trends Biochem Sci. 2012;37(12):553-562.

21. Ulloa L, Messmer D. High-mobility group box 1 (HMGB1) protein: friend and foe. Cytokine Growth Factor Rev. 2006 Jun;17(3):189-201.

22. Ramasamy R, Yan SF, Herold K, Clynes R, Schmidt AM. Receptor for advanced glycation end products: fundamental roles in the inflammatory response: winding the way to the pathogenesis of endothelial dysfunction and atherosclerosis. Ann N Y Acad Sci. 2008 Apr;1126:7-13.

23. Musumeci D, Roviello GN, Montesarchio D. An overview on HMGB1 inhibitors as potential therapeutic agents in HMGB1-related pathologies. Pharmacol Ther. Elsevier Inc.; 2014 Mar;141(3):347-357.

24. Yang H, Wang H, Czura CJ, Tracey KJ. The cytokine activity of HMGB1. J Leukoc Biol. 2005 Jul;78(1):1-8.

25. Thomas JO, Stott K. H1 and HMGB1: modulators of chromatin structure. Biochem Soc Trans. 2012 Apr;40(2): 341-346.

26. Scaffidi $\mathrm{P}$, Misteli T, Bianchi ME. Release of chromatin protein HMGB1 by necrotic cells triggers inflammation. Nature. 2002 Jul;418(6894):191-195.

27. Yang Q, Wang J-Z, Li J-C, Zhou Y, Zhong Q, Lu F-L, et al. High-mobility group protein box-1 and its relevance to cerebral ischemia. J Cereb blood flow Metab. Nature Publishing Group; 2010 Feb;30(2):243-254.

28. Agnello D, Wang H, Yang H, Tracey KJ, Ghezzi P. HMGB-1, a DNA-binding protein with cytokine activity, induces brain TNF and IL- 6 production, and mediates anorexia and taste aversion. Cytokine. 2002 May 21;18(4):231-236.

29. O'Connor KA, Hansen MK, Rachal Pugh C, Deak MM, Biedenkapp JC, Milligan ED, et al. Further characterization of high mobility group box 1 (HMGB1) as a proinflammatory cytokine: central nervous system effects. Cytokine. 2003 Dec 21;24(6):254-265.

30. Faraco G, Fossati S, Bianchi ME, Patrone M, Pedrazzi M, Sparatore $B$, et al. High mobility group box 1 protein is released by neural cells upon different stresses and worsens ischemic neurodegeneration in vitro and in vivo. J Neurochem. 2007 Oct;103(2):590-603.

31. Zhou P, Li Y, Li W, Han T, Yang S, Yao Y, et al. [Changes in serum high mobility group box-1 protein and high-sensitivity C-reactive protein in patients with acute cerebral infarction and their clinical significance]. Zhongguo Wei Zhong Bing Ji Jiu Yi Xue. 2012 May;24(5):265-268.

32. Kim J-B, Sig Choi J, Yu Y-M, Nam K, Piao C-S, Kim S-W, et al. HMGB1, a novel cytokine-like mediator linking acu- te neuronal death and delayed neuroinflammation in the postischemic brain. J Neurosci. 2006 Jun 14;26(24): 6413-6421.

33. Bonanno G, Raiteri L, Milanese M, Zappettini S, Melloni $E$, Pedrazzi $M$, et al. The high-mobility group box 1 cytokine induces transporter-mediated release of glutamate from glial subcellular particles (gliosomes) prepared from in situ-matured astrocytes. Int Rev Neurobiol. 2007 Jan;82:73-93.

34. Moskowitz MA, Lo EH, ladecola C. The Science of Stroke: Mechanisms in Search of Treatments. Neuron. 2010;67(2):181-198.

35. Hayakawa K, Qiu J, Lo EH. Biphasic actions of HMGB1 signaling in inflammation and recovery after stroke. Ann N Y Acad Sci. 2010 Oct;1207:50-57.

36. Qiu J, Xu J, Zheng Y, Wei Y, Zhu X, Lo EH, et al. High-mobility group box 1 promotes metalloproteinase- 9 upregulation through Toll-like receptor 4 after cerebral ischemia. Stroke. 2010 Sep;41(9):2077-2082.

37. Kim J-B, Lim C-M, Yu Y-M, Lee J-K. Induction and subcellular localization of high-mobility group box-1 (HMGB1) in the postischemic rat brain. J Neurosci Res. 2008 Apr;86(5):1125-1131.

38. Qiu J, Nishimura M, Wang Y, Sims JR, Qiu S, Savitz SI, et al. Early release of HMGB-1 from neurons after the onset of brain ischemia. J Cereb Blood Flow Metab. 2008 May;28(5):927-938.

39. Fiuza C, Bustin M, Talwar S, Tropea M, Gerstenberger E, Shelhamer JH, et al. Inflammation-promoting activity of HMGB1 on human microvascular endothelial cells. Blood. 2003 Apr 1;101(7):2652-2660.

40. Dumitriu IE, Baruah P, Manfredi AA, Bianchi ME, RovereQuerini P. HMGB1: guiding immunity from within. Trends Immunol. 2005 Jul;26(7):381-387.

41. Höhne C, Wenzel M, Angele B, Hammerschmidt S, Häcker $\mathrm{H}$, Klein $\mathrm{M}$, et al. High mobility group box 1 prolongs inflammation and worsens disease in pneumococcal meningitis. Brain. 2013 Jun;136(Pt 6):1746-1759.

42. Zhu X-D, Chen J-S, Zhou F, Liu Q-C, Chen G, Zhang J-M. Relationship between plasma high mobility group box-1 protein levels and clinical outcomes of aneurysmal subarachnoid hemorrhage. J Neuroinflammation. 2012 Jan;9:194.

43. Nakahara T, Tsuruta R, Kaneko T, Yamashita S, Fujita M, Kasaoka $S$, et al. High-mobility group box 1 protein in CSF of patients with subarachnoid hemorrhage. Neurocrit Care. 2009 Dec;11(3):362-368.

44. Asano T, Ichiki K, Koizumi S, Kaizu K, Hatori T, Mashiko $\mathrm{K}$, et al. High mobility group box 1 in cerebrospinal fluid from several neurological diseases at early time points. Int J Neurosci. 2011 Aug;121(8):480-484.

45. Ostberg T, Wähämaa H, Palmblad K, Ito N, Stridh P, Shoshan $\mathrm{M}$, et al. Oxaliplatin retains HMGB1 intranuclearly and ameliorates collagen type II-induced arthritis. Arthritis Res Ther. 2008 Jan;10(1):R1.

46. Zhu S, Li W, Ward MF, Sama AE, Wang H. High mobility group box 1 protein as a potential drug target for infection- and injury-elicited inflammation. Inflamm Allergy Drug Targets. 2010 Mar;9(1):60-72.

47. Gentile LF, Moldawer LL. HMGB1 as a therapeutic target for sepsis: it's all in the timing! Expert Opin Ther Targets. Informa UK, Ltd. London; 2014 Jan. 
48. Wang H, Ward MF, Sama AE. Novel HMGB1-inhibiting therapeutic agents for experimental sepsis. Shock. 2009 Oct;32(4):348-357.

49. Davé SH, Tilstra JS, Matsuoka K, Li F, DeMarco RA, Beer -Stolz D, et al. Ethyl pyruvate decreases HMGB1 release and ameliorates murine colitis. J Leukoc Biol. 2009 Sep;86(3):633-643.

50. Kim I-D, Shin J-H, Lee H-K, Jin Y-C, Lee J-K. Intranasal delivery of HMGB1-binding heptamer peptide confers a robust neuroprotection in the postischemic brain. Neurosci Lett. Elsevier Ireland Ltd; 2012 Sep;525(2):179-183.

51. Wang L, Zhang X, Liu L, Yang R, Cui L, Li M. Atorvastatin protects rat brains against permanent focal ischemia and downregulates HMGB1, HMGB1 receptors (RAGE and TLR4), NF-kappaB expression. Neurosci Lett. 2010 Mar 8;471(3):152-156.

52. Okuma Y, Liu K, Wake H, Zhang J, Maruo T, Date I, et al. Anti-high mobility group box-1 antibody therapy for traumatic brain injury. Ann Neurol. 2012 Sep;72(3): 373-384.
53. Uzawa A, Mori M, Taniguchi J, Masuda S, Muto M, Kuwabara S. Anti-high mobility group box 1 monoclonal antibody ameliorates experimental autoimmune encephalomyelitis. Clin Exp Immunol. 2013 Apr;172(1):37-43.

Acceptance for editing: 2014-12-10 Acceptance for publication: 2014-12-31

Correspondence address: Norbert Wąsik 26/28 Kościelna Street 60-538 Poznań, Poland phone: 502949248 email: norbertwasik@gmail.com 